\title{
Valence photoelectron spectra of alkali bromides calculated within the propagator theory
}

\author{
Karpenko, Alexander; lablonskyi, Denys; Aksela, Helena
}

Published in:

Journal of Chemical Physics

Link to article, DOI:

$10.1063 / 1.4802054$

Publication date:

2013

Document Version

Publisher's PDF, also known as Version of record

Link back to DTU Orbit

Citation (APA):

Karpenko, A., lablonskyi, D., \& Aksela, H. (2013). Valence photoelectron spectra of alkali bromides calculated within the propagator theory. Journal of Chemical Physics, 138(16), 164315. https://doi.org/10.1063/1.4802054

\section{General rights}

Copyright and moral rights for the publications made accessible in the public portal are retained by the authors and/or other copyright owners and it is a condition of accessing publications that users recognise and abide by the legal requirements associated with these rights.

- Users may download and print one copy of any publication from the public portal for the purpose of private study or research.

- You may not further distribute the material or use it for any profit-making activity or commercial gain

- You may freely distribute the URL identifying the publication in the public portal 


\section{AIP}

\section{Valence photoelectron spectra of alkali bromides calculated within the propagator theory}

Alexander Karpenko, Denys lablonskyi, and Helena Aksela

Citation: J. Chem. Phys. 138, 164315 (2013); doi: 10.1063/1.4802054

View online: http://dx.doi.org/10.1063/1.4802054

View Table of Contents: http://jcp.aip.org/resource/1/JCPSA6/v138/i16

Published by the American Institute of Physics.

\section{Additional information on J. Chem. Phys.}

Journal Homepage: http://jcp.aip.org/

Journal Information: http://jcp.aip.org/about/about_the_journal

Top downloads: http://jcp.aip.org/features/most_downloaded

Information for Authors: http://jcp.aip.org/authors

\section{ADVERTISEMENT}

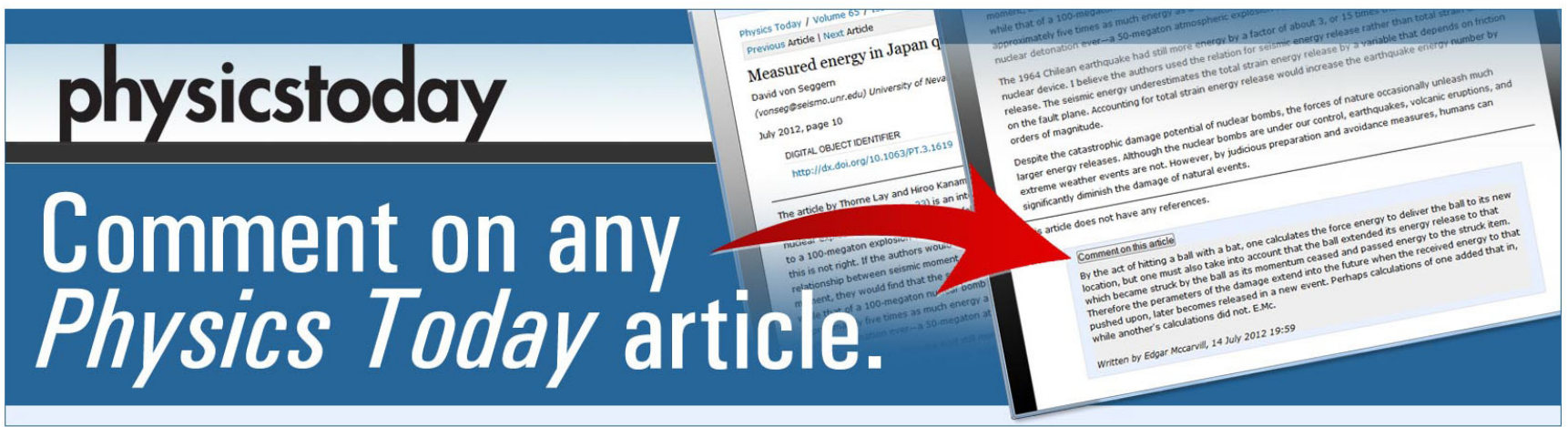




\title{
Valence photoelectron spectra of alkali bromides calculated within the propagator theory
}

\author{
Alexander Karpenko, ${ }^{1,2, a)}$ Denys lablonskyi, ${ }^{1}$ and Helena Aksela ${ }^{1}$ \\ ${ }^{1}$ Department of Physical Sciences, University of Oulu, P.O. Box 3000, Fin-90014 Oulu, Finland \\ ${ }^{2}$ Center for Atomic-Scale Materials Design (CAMD), Department of Physics, Technical University \\ of Denmark, Building 307, DK-2800 Kgs. Lyngby, Denmark
}

(Received 19 December 2012; accepted 3 April 2013; published online 25 April 2013)

\begin{abstract}
The valence ionization spectra covering the binding energy range $0-45 \mathrm{eV}$ of alkali bromide $\mathrm{XBr}(\mathrm{X}=\mathrm{Li}, \mathrm{Na}, \mathrm{K}, \mathrm{Rb})$ vapors are studied within the framework of the propagator theory. Relativistic Algebraic Diagrammatic Construction calculations have been carried out in order to investigate photoionization processes and to describe molecular electronic structure. Theoretical results are compared with available experimental data. (c) 2013 AIP Publishing LLC. [http://dx.doi.org/10.1063/1.4802054]
\end{abstract}

\section{INTRODUCTION}

Ionization processes of alkali halide vapors have been studied by photoelectron (PE) spectroscopy technique for the last four decades. ${ }^{1,2}$ The technique gives information about electronic structure and provides chemical characterization of alkali halide microclusters. ${ }^{3}$ The valence PE spectra of alkali halides have been recorded earlier, with HeI, HeII discharge lamp excitation. ${ }^{4-6}$ During the last decade the use of synchrotron radiation (SR) as an exciting source has become a standard technique in electron spectroscopy of alkali halide vapors. ${ }^{7-9}$

Nowadays, computational methods have become an important approach to understand chemical bonds of molecular systems, as well as to help in interpretation of experimental PE spectra. Accurate calculation of PE spectra of alkali halides, containing heavy elements $(\mathrm{Br}$ and $\mathrm{Rb})$ with significant spin-orbit splitting and electron correlation, is a challenging task. The relativistic methods are a natural way of treating such systems.

Tomasello et al. investigated the vertical valence ionization potentials of the $(\mathrm{NaCl})_{2}$ dimer by means of two allelectron ab initio self-consistent field-HF (SCF-HF) based Green's function (GF) methods. ${ }^{10}$

More recently, Pernpointner et al. ${ }^{11}$ carried out calculations of alkali iodide valence PE spectra in order to reproduce experimental valence ionization spectra. Fully relativistic calculations for the ionization spectra of hydrogen iodide (HI) and alkali iodides $\mathrm{MI}(\mathrm{M}=\mathrm{Li}, \mathrm{Na}, \mathrm{K}, \mathrm{Rb})$ were carried out using a one-particle propagator technique in a four-component framework. Pernpointner et al. ${ }^{12}$ investigated by means of relativistic computations of ionization spectra of small $(\mathrm{HI})_{2}$, $(\mathrm{LiI})_{2}$ clusters, and subsequent electronic decay of cations.

In this work, we investigated valence photoelectron spectra of alkali bromides. By using the third-order algebraic diagrammatic construction (ADC(3)) method we calculated the binding energies and ionization strengths for $4 p$ and $4 s$ orbitals of $\mathrm{Br}^{-}, 3 p$ and $3 s$ orbitals of $\mathrm{K}^{+}, 2 p$ orbital of $\mathrm{Na}^{+}$, and

\footnotetext{
a)Electronic mail: oleksandr.karpenko@oulu.fi
}

$4 p$ and $4 s$ orbitals of $\mathrm{Rb}^{+}$. For $\mathrm{KBr}$ this is a continuation of an earlier study by Caló et al., ${ }^{9}$ who performed calculations based on configuration interaction (CI) and multiconfigurational self-consistent field (MCSCF) methods for ionization energies.

For $\mathrm{KBr}$, we found theoretical ionization energies to be in close agreement with experimental data ${ }^{9}$ taken using synchrotron radiation source. $\mathrm{ADC}(3)$ calculations for $\mathrm{LiBr}$, $\mathrm{NaBr}$, and $\mathrm{RbBr}$ are expected to be similarly accurate and may support future experiments. To the best of our knowledge no experimental inner-valence ionization spectra of these molecules are available so far.

\section{THEORY AND COMPUTATIONS}

Green's function methods represent a very useful tool for calculation of the electron ionization potentials, electron affinities, excitation energies, and other properties. In the literature there are two major Green's function approaches to investigate the ionization process: an outer-valence Green's function (OVGF) approximation ${ }^{13,14}$ and second- or thirdorder algebraic diagrammatic construction. ${ }^{15}$ The overview of Green's function methods can be found in Ref. 16.

$\mathrm{ADC}$ is an approximation scheme which is the most practical and systematic for Green's function evaluation. The problem of finding the pole positions and pole strengths of a Green's function is formulated in terms of the solution of a matrix eigenvalue problem. Originally, the method was formulated by J. Schirmer. ${ }^{15}$ A more detailed discussion of the ADC scheme can be found in Refs. 17 and 18.

Spectral intensities, which are measured in the photoelectron experiment are related to transition probability amplitudes. They are related to the one particle Green's function. In energy representation GF can be expressed in the form of spectral representation

$$
G_{p q}(\omega)=G_{p q}^{+}(\omega)+G_{p q}^{-}(\omega),
$$

where $G_{p q}^{+}(\omega), \quad G_{p q}^{-}(\omega)$ represent information about $(N \pm 1)$-particle systems, respectively. $(N-1)$ particle part 
corresponds to singly ionized system and can be written in the form

$$
G_{p q}^{-}(\omega)=\sum_{n} \frac{x_{n q}^{*} x_{n p}}{\omega-\omega_{n}-i \eta},
$$

where the poles $\omega_{n}$,

$$
\omega_{n}=-\left(E_{n}^{N-1}-E_{0}^{N}\right),
$$

are the $n$th ionization energies of the system and $x_{n p}$ are the transition probability amplitudes

$$
x_{n p}=\left\langle\Psi_{n}^{N-1}\left|c_{p}\right| \Psi_{0}^{N}\right\rangle .
$$

The simplest form of the (relative) photoelectron spectral intensities $P_{n}$ can be evaluated as

$$
P_{n} \sim \sum_{p}\left|x_{p}^{(n)}\right|^{2} .
$$

All calculations have been performed using the fully relativistic one-particle propagator framework RELADC ${ }^{19,20} \mathrm{im}$ plemented in DIRAC10. ${ }^{21}$ The calculations for molecules have been carried out in $C_{2 v}$ double-group symmetry. The spin-orbit coupling was discernible directly from the relativistic treatment.

The molecular bond lengths were taken from the experimental data, $2.17 \AA^{22}$ for $\mathrm{LiBr}, 2.50 \AA^{23}$ for $\mathrm{NaBr}, 2.915 \AA^{9}$ for $\mathrm{KBr}$, and $2.94 \AA^{24}$ for $\mathrm{RbBr}$.

For calculations of lithium, sodium, and potassium the $6-311++\mathrm{G}(2 \mathrm{~d}, 2 \mathrm{p})$ basis $\operatorname{set}^{25-27}$ has been used from the DIRAC10 basis library. Bromine and rubidium have been studied using the valence quadruple-zeta dyall.av $4 z$ basis set being developed by Ken Dyall. ${ }^{28}$ Four-component Dirac-
Coulomb Hamiltonian was chosen for all ADC(3) calculations. Gaunt corrections were included for self-consistentfield ground-state calculation. Effects from small components integrals contribution are neglected.

\section{RESULTS AND DISCUSSION}

\section{A. Photoelectron spectra of $\mathbf{K B r}$}

At first, we compare our calculated results with available experimental data for ionization energies of potassium bromide. The experimental photoelectron spectrum of $\mathrm{KBr}$ shown in Fig. 1(a) was published by Caló et al. ${ }^{9}$ The spectrum was recorded at photon energy of $61.5 \mathrm{eV}$ at beamline I411 in MAX-laboratory, Lund, Sweden. The main structures seen at the ionization energies around 9, 19, 25, 41, and $11 \mathrm{eV}$ were marked with capital letters A, B, C, D, and E, respectively. Our theoretical spectrum in Fig. 1(b) was obtained by convoluting the calculated pole strengths with Gaussian and Lorentzian profiles, $250 \mathrm{meV}$ each. Atomic configurations were assigned to spectral structures, according to main contribution to molecular orbitals (MO).

Comparison between theoretical and experimental ionization energies is summarized in Table I. In the first column singly ionized states are presented according to the leading atomic contribution to the molecular orbital. CI and MCSCF calculations taken from Ref. 9 are shown in the second column.

There are three molecular-field-split ${ }^{2} \Pi_{3 / 2},{ }^{2} \Pi_{1 / 2}$, and ${ }^{2} \Sigma_{1 / 2}$ states in the $\mathrm{Br} 4 p$ valence region. A Mulliken population analysis yielded a potassium contribution of $2 \%$ to ${ }^{2} \Sigma_{1 / 2}$

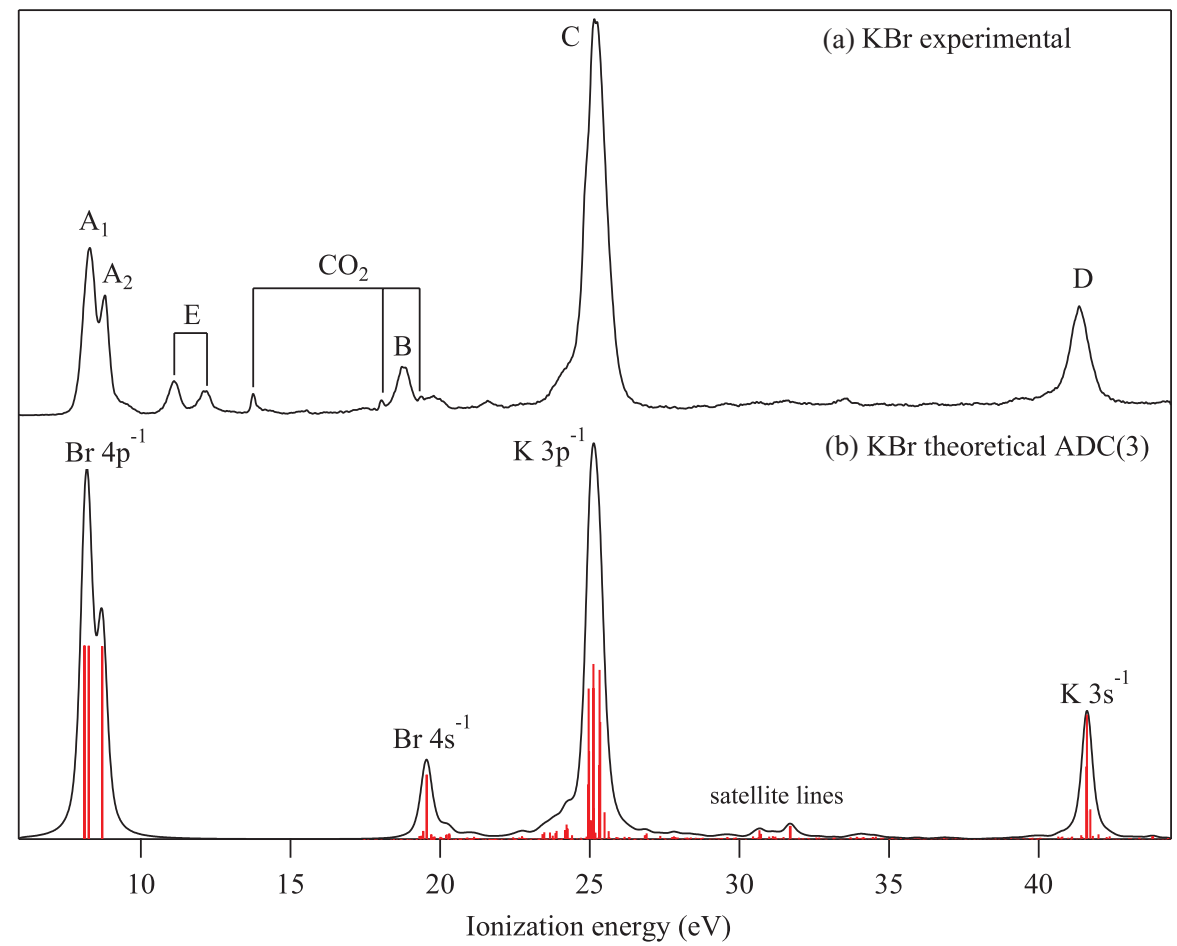

FIG. 1. (a) Experimental valence photoelectron spectrum of $\mathrm{KBr}$ molecule measured at 61.5 eV photon energy. (b) The fully relativistic calculated ionization spectrum of $\mathrm{KBr}$ molecule at the ADC(3) level convoluted with Lorentzian and Gaussian profiles. 
TABLE I. Comparison between experimental energies and theoretical results for singly ionized states taken from the CI, MCSCF, and fully relativistic $\mathrm{ADC}(3)$ calculations. All values are given in electronvolts.

\begin{tabular}{|c|c|c|c|}
\hline \multirow[b]{2}{*}{ Lead. config. } & \multicolumn{3}{|c|}{ Ionization energy } \\
\hline & $\mathrm{CI} / \mathrm{MCSCF}$ & $\operatorname{ADC}(3)$ & Expt. $^{a}$ \\
\hline $\operatorname{Br}\left(4 p^{-1}\right)^{2} \Pi_{3 / 2}$ & $7.07^{\mathrm{b}}$ & 8.12 & 8.29 \\
\hline${ }^{2} \Pi_{1 / 2}$ & $7.25^{\mathrm{b}}$ & 8.26 & 8.29 \\
\hline${ }^{2} \Sigma_{1 / 2}$ & $7.89^{\mathrm{b}}$ & 8.71 & 8.80 \\
\hline $\operatorname{Br}\left(4 s^{-1}\right)$ & $21.90^{\mathrm{c}}$ & 19.45 & 18.84 \\
\hline $\mathrm{K}\left(3 p^{-1}\right)$ & $27.26^{c}$ & 25.10 & 25.17 \\
\hline $\mathrm{K}\left(3 s^{-1}\right)$ & $48.18^{\mathrm{c}}$ & 41.90 & 41.35 \\
\hline
\end{tabular}

${ }^{\mathrm{a}}$ Experimental data from Ref. 9.

${ }^{\mathrm{b}} \mathrm{CI}$ calculation from Ref. 9 .

${ }^{\mathrm{c}} \mathrm{MCSCF}+\mathrm{SO}$ calculation from Ref. 9 .

state whereas ${ }^{2} \Pi_{3 / 2},{ }^{2} \Pi_{1 / 2}$ states were found to exclusively exhibit a bromine character.

The average deviation of ionization energy, obtained by CI method for the first three peaks of the outer-valence region up to $15 \mathrm{eV}$ is around $1 \mathrm{eV}$ in comparison to the experimental value, whereas $\mathrm{ADC}(3)$ method reproduced obtained energies within $0.1 \mathrm{eV} .{ }^{2} \Pi_{3 / 2}{ }^{2} \Pi_{1 / 2}$ splitting of $\mathrm{KBr}$ was not resolved experimentally. $\mathrm{ADC}(3)$ calculations predicted that the splitting is approximately $0.14 \mathrm{eV}$ (Fig. 1(b)).

The double peak structure at $11.1 \mathrm{eV}$ and $12.1 \mathrm{eV}$ indicated as $\mathrm{E}$ in Fig. 1(a) has been identified as $\mathrm{Br} 3 d$ photolines ${ }^{9}$ arising from the small second order contribution of the monochromator $(123 \mathrm{eV})$.

In the inner-valence region around $15-30 \mathrm{eV}$, there are two peaks B and C (see Fig. 1(a)) which originate mainly from $\mathrm{Br} 4 s$ and $\mathrm{K} 3 p$ atomic orbitals, respectively. Ionization energies for $\mathrm{B}$ and $\mathrm{C}$ peaks predicted by $\mathrm{CI}$ and $\mathrm{ADC}(3)$ methods deviate from experiment in average by $2.3 \mathrm{eV}$ and $0.3 \mathrm{eV}$, respectively. Configuration interaction method used by Caló et al. ${ }^{9}$ fails in reproducing ionization energy for peaks originating from the K $3 s$ atomic orbital (peak D in Fig. 1(a)). Ionization energy for that peak deviates by $7.6 \mathrm{eV}$ from the experimental value of $41.35 \mathrm{eV}$, whereas $\mathrm{ADC}(3)$ agrees within $0.6 \mathrm{eV}$.

In the inner-valence region $20-45 \mathrm{eV}$ we see a dense structure of additional satellites lines. These lines predominantly occur due to coupling of two-hole-one-particle ( $2 \mathrm{~h} 1 \mathrm{p}$ ) configurations with the initial main one-hole (1h) state. This phenomenon leads to the distribution of the intensity of the main line over several satellite lines. ADC method provides information about electron correlated states, where final cationic state is seen as linear combination of $1 \mathrm{~h}, 2 \mathrm{~h} 1 \mathrm{p}, 3 \mathrm{~h} 2 \mathrm{p}$...excited configurations. More discussions about satellites structures can be found in Refs. 9 and 11 .

Intensity distribution across the binding energy region is based on occupation of orbitals (statistical weights) in present calculations as actual values of dipole matrix elements are omitted. However, as seen from a comparison between experiment and theory, if energies are well predicted, assignment of all structures becomes possible.

\section{B. Photoelectron spectra of $\mathrm{LiBr}, \mathrm{NaBr}, \mathrm{KBr}$, and $\mathrm{RbBr}$}

$\mathrm{ADC}(3)$ calculated ionization spectra of the outer and inner-valence regions of the $\mathrm{LiBr}, \mathrm{NaBr}, \mathrm{KBr}$, and $\mathrm{RbBr}$ molecules are shown in Figs. 2(a)-2(d), respectively. Calculated and experimentally obtained energies for three outermost cationic states of different alkali bromides are compared with available experimental results ${ }^{6}$ and collected in Table II. A similar analysis of the electronic structures of alkali iodide monomers was presented in Ref. 11.

The outer-valence electronic structure of alkali bromides, as well as alkali iodides, has identical character and consists of three ligand-field split cationic states, originating from $\pi$ and $\sigma$ molecular orbitals with pronounced $\mathrm{Br} 4 p$ character. Inner-valence region includes features which originate from $4 s$ orbital of atomic $\mathrm{Br}$ and from $p$ orbitals of alkali atom. Cross section studies by Price, Potts, and Streets ${ }^{29}$ showed that molecular orbitals resulting largely from $p$ atomic orbitals have larger HeI photon cross sections than those resulting predominantly from $s$ atomic orbitals. Thus, one would expect $\pi_{3 / 2}, \pi_{1 / 2}$, and $\sigma_{1 / 2}$ bands with atomic $p$ origin to be of the same intensity and shape and to be stronger than $\sigma$ band of atomic $s$ origin. So, we would expect to see similar intensity ratio for the valence peaks of $\mathrm{LiBr}, \mathrm{NaBr}, \mathrm{RbBr}$ than what was measured for $\mathrm{KBr}$ (see Fig. 1(a)).

In the valence region $0-15 \mathrm{eV}$ three cationic states with pole strength of 0.94 are clearly visible. The outermost two spin-orbit split ${ }^{2} \Pi_{3 / 2},{ }^{2} \Pi_{1 / 2}$ states originated mainly from $\mathrm{Br}$ atom, whereas ${ }^{2} \Sigma_{1 / 2}$ additionally has a small alkali metal contribution. The highest alkali metal contribution to ${ }^{2} \Sigma_{1 / 2}$ state, about $11 \%$, was calculated for $\mathrm{LiBr}$, whereas for other alkali halides the metal contribution is less than $2 \%$. Moreover, $2 \%$ metal contribution to ${ }^{2} \Pi_{1 / 2}$ state was calculated for LiBr. All the outer-valence states are in good agreement with the oneparticle picture of the ionization process.

As seen from Table III, for the outermost state ${ }^{2} \Pi_{3 / 2}$, the contribution of atomic $\mathrm{Br} p_{x}$ and $\mathrm{Br} p_{y}$ subshells is $98 \%$ for all molecules. In contrast, ${ }^{2} \Pi_{1 / 2}$ and ${ }^{2} \Sigma_{1 / 2}$ states are totally mixed from $p_{x}, p_{y}, p_{z}$ atomic subshells of bromine. Thus, we could assign them to ${ }^{2} \Pi$ or ${ }^{2} \Sigma$ states only on the basis of the main atomic contribution to molecular orbital. The $p_{z}$ contribution to ${ }^{2} \Pi_{1 / 2}$ state is increasing in going to heavier metal atom. The reverse situation occurs for ${ }^{2} \Sigma_{1 / 2}$ state, where $p_{z}$ contribution is about $77 \%$ for $\mathrm{LiBr}$ and decreases to $54 \%$ for $\mathrm{RbBr}$. One would expect to find ${ }^{2} \Sigma_{1 / 2}$ at lower ionization energy than ${ }^{2} \Pi_{1 / 2}$ for CsBr molecule.

In terms of partial ionic character, increased polarization of the halogen atom is related to increased covalent character of the metal-halogen bond. ${ }^{5}$ Going from $\mathrm{LiBr}$ to $\mathrm{RbBr}$ the chemical bond becomes more ionic and less covalent.

While the outer-valence ionization spectra of $\mathrm{LiBr}, \mathrm{NaBr}$, $\mathrm{KBr}$, and $\mathrm{RbBr}$ have been published before ${ }^{5,6,9}$ the innervalence structures have not been discussed earlier in details. We will first take a look at the main inner-valence peak structures of $\mathrm{LiBr}, \mathrm{NaBr}$, and $\mathrm{RbBr}$ separately and later on we will follow the tendency of spectral features in general for $\mathrm{LiBr}$ to $\mathrm{RbBr}$. Inner shell region of $\mathrm{KBr}$ was already discussed above and will only be included when discussing the evolution of the inner-valence features. 

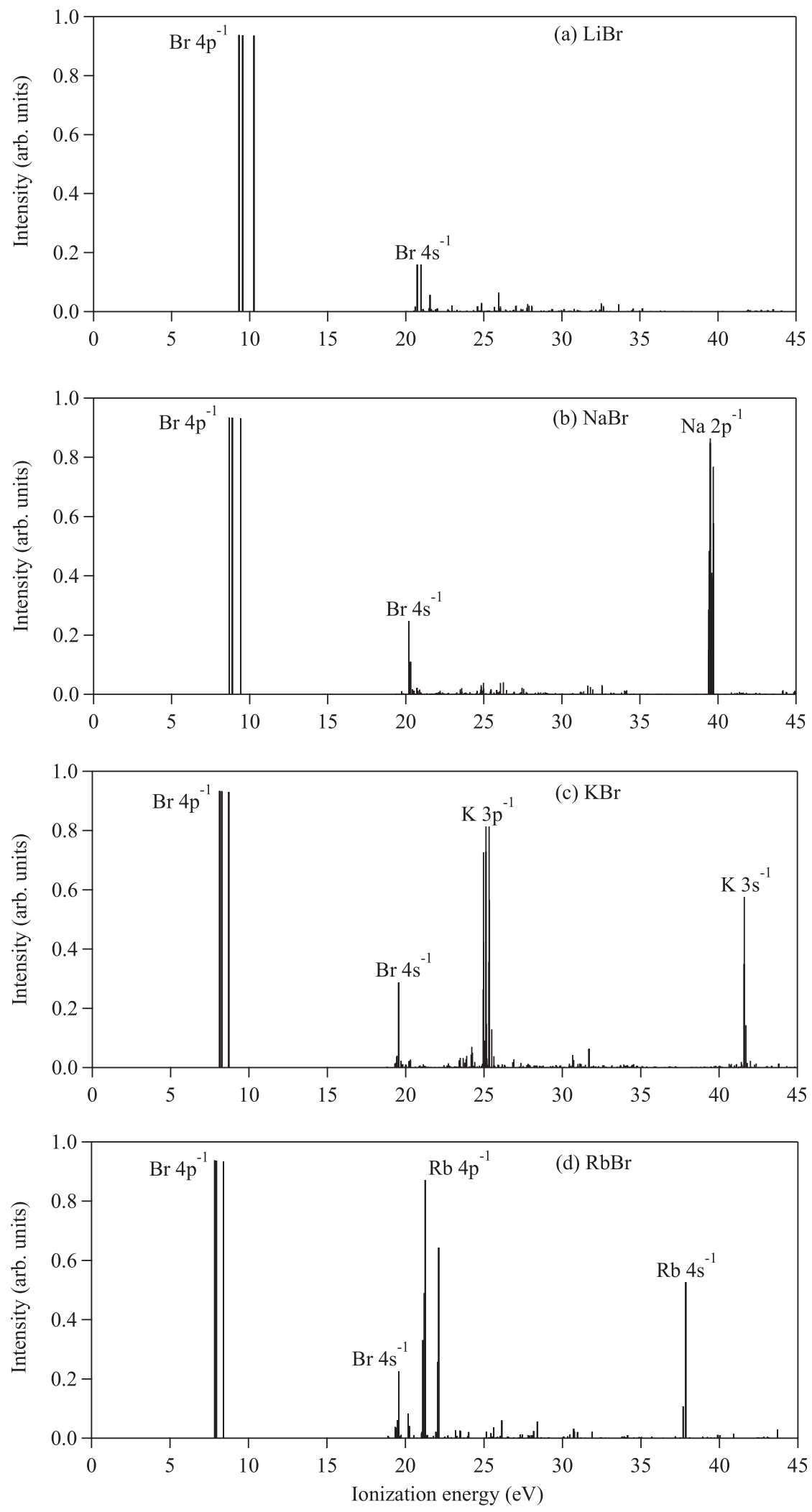

FIG. 2. The fully relativistic calculated ionization spectra of $\mathrm{LiBr}(\mathrm{a}), \mathrm{NaBr}$ (b), $\mathrm{KBr}$ (c), and $\mathrm{RbBr}(\mathrm{d})$, at the $\mathrm{ADC}(3)$ level.

$\mathrm{ADC}(3)$ calculations for $\mathrm{LiBr}$ predict that one would find a peak, which originates from $\mathrm{Br} 4 s$ atomic orbital, around $20.8 \mathrm{eV}$ (see Fig. 2(a)). $\mathrm{Br} 4 s^{-1}$ peak breaks down to two close lying lines due to many-body interaction. In addition, a dense set of satellite lines accompanies the main $\mathrm{Br} 4 s^{-1}$.
The atomic contributions to the $\mathrm{Br} 4 s^{-1}$ peak, according to Mulliken population analysis are $95 \%$ of $\mathrm{Br} 4 s$ and $3 \%$ of Li $1 s$ orbitals.

The calculated spectrum of $\mathrm{NaBr}$ (see Fig. 2(b)) shows two peaks lying at around $20.2 \mathrm{eV}$ and $39.5 \mathrm{eV}$, which 
TABLE II. Theoretical ADC(3) and experimental energies (in eV) of three outer valence cationic states of $\mathrm{XBr}(\mathrm{X}=\mathrm{Li}, \mathrm{Na}, \mathrm{K}, \mathrm{Rb})$ compounds.

\begin{tabular}{lccrrrrr} 
& \multicolumn{3}{c}{ Theoretical } & & \multicolumn{3}{c}{ Experimental $^{\mathrm{a}}$} \\
\cline { 2 - 4 } \cline { 7 - 8 } & ${ }^{2} \Pi_{3 / 2}$ & ${ }^{2} \Pi_{1 / 2}$ & ${ }^{2} \Sigma_{1 / 2}$ & & ${ }^{2} \Pi_{3 / 2}$ & ${ }^{2} \Pi_{1 / 2}$ & ${ }^{2} \Sigma_{1 / 2}$ \\
\hline $\mathrm{LiBr}$ & 9.31 & 9.55 & 10.28 & & 10.00 & 10.60 & 11.60 \\
$\mathrm{NaBr}$ & 8.70 & 8.89 & 9.43 & & 8.70 & 9.40 & 10.30 \\
$\mathrm{KBr}$ & 8.12 & 8.26 & 8.71 & & 8.10 & 8.60 & 9.30 \\
$\mathrm{RbBr}$ & 7.84 & 7.95 & 8.39 & & 8.00 & 8.40 & 8.80 \\
\hline \hline
\end{tabular}

${ }^{\mathrm{a}}$ Reference 6.

correspond to $\mathrm{Br} 4 s$ and $\mathrm{Na} 2 p$ atomic orbitals, respectively. Mulliken population analysis predicts contribution to the $\mathrm{Br}$ $4 s^{-1}$ peak to be about $99 \%$ of $\mathrm{Br} 4 s$ atomic orbital.

The calculated spectrum of $\mathrm{RbBr}$ is presented in Fig. 2(d). In the inner-valence region the main structures are seen around $19.6 \mathrm{eV}, 21.3 \mathrm{eV}, 22.1 \mathrm{eV}$, and $37.9 \mathrm{eV}$. They correspond to $\mathrm{Br} 4 s, \mathrm{Rb} 4 p_{3 / 2}, \mathrm{Rb} 4 p_{1 / 2}$, and $\mathrm{Rb} 4 s$ orbitals, respectively.

Inspection of Fig. 2 shows, that in going from $\mathrm{NaBr}$ to $\mathrm{RbBr}$, the $n p^{-1}$ peak ( $\mathrm{n}=2$ for $\mathrm{Na}, 3$ for $\mathrm{K}$, and 4 for $\mathrm{Rb}$ ) approaches the $4 p^{-1}$ peak of $\mathrm{Br}$. At the same time, the splitting inside the peaks increases heavily. The peak also overlaps more and more with the satellite peak structure accompanying the $\mathrm{Br} 4 s^{-1}$ peak. Many-body effects clearly play a strong role in the inner-valence region due to near degeneracy of several molecular states.

It is a challenging task to correctly predict the spectral features in case of strong electron correlation. The density and ionization distribution strongly depend on the number of Lanczos iterations and choosing a basis set in ADC(3) calculations. Overall tendency is clear, as one can see, that quite isolated core-valence $\mathrm{Na} 2 p^{-1}$ peak (see Fig. 2(b)) breaks down to several lines. This effect cannot be described in terms of one electron picture. Even more pronounced breakdown of single particle picture happens for $\mathrm{KBr}$ and $\mathrm{RbBr}$ molecules. The K $3 p^{-1}$ and $\mathrm{Rb} 4 p^{-1}$ peaks (see Figs. 2(c) and 2(d), respectively) shift to lower ionization energies, where they heavily overlap with $\mathrm{Br} 4 s^{-1}$ satellite lines. They also affect the position of $\mathrm{Br} 4 s^{-1}$ main line. Near degeneracy of states leads to a mixing which shifts $\mathrm{Br} 4 s^{-1}$ peak towards $\mathrm{Br} 4 p^{-1}$ peaks.

TABLE III. Bromine $p_{x}, p_{y}, p_{z}$ atomic contribution to the first three outervalence MO-spinors based on Mulliken population analysis at the DiracHartree-Fock (DHF)-level. All values are given in (\%). Contributions smaller than $1 \%$ and contributions from alkali metal are not included.

\begin{tabular}{|c|c|c|c|c|c|c|}
\hline \multirow[b]{3}{*}{ Molecule } & \multicolumn{6}{|c|}{ Population } \\
\hline & \multicolumn{2}{|c|}{${ }^{2} \Pi_{3 / 2}$} & \multicolumn{2}{|c|}{${ }^{2} \Pi_{1 / 2}$} & \multicolumn{2}{|c|}{${ }^{2} \Sigma_{1 / 2}$} \\
\hline & $p_{x}+p_{y}$ & $p_{z}$ & $p_{x}+p_{y}$ & $p_{z}$ & $p_{x}+p_{y}$ & $p_{z}$ \\
\hline $\mathrm{LiBr}$ & 98 & $\ldots$ & 86 & 10 & 12 & 77 \\
\hline $\mathrm{NaBr}$ & 98 & $\ldots$ & 76 & 23 & 24 & 74 \\
\hline $\mathrm{KBr}$ & 98 & $\ldots$ & 62 & 36 & 38 & 61 \\
\hline $\mathrm{RbBr}$ & 98 & $\ldots$ & 56 & 41 & 42 & 54 \\
\hline
\end{tabular}

TABLE IV. Comparison of the spin-orbit splittings of $\mathrm{Na}, \mathrm{K}$, and $\mathrm{Rb} n p^{-1}$ $(n=2,3,4)$ peaks in $\mathrm{XBr}(\mathrm{X}=\mathrm{Na}, \mathrm{K}, \mathrm{Rb})$ molecules with atomic spin-orbit splittings.

\begin{tabular}{lccc}
\hline \hline & $\mathrm{Na} 2 p^{-1}$ & $\mathrm{~K} 3 p^{-1}$ & $\mathrm{Rb} \mathrm{4p^{-1 }}$ \\
\hline Molecule & 0.26 & 0.36 & 0.86 \\
Atom $^{30}$ & 0.27 & 0.36 & 0.69 \\
\hline \hline
\end{tabular}

Next, we will compare calculated $\mathrm{ADC}(3)$ spin-orbit splittings of $\mathrm{Na}, \mathrm{K}$, and $\mathrm{Rb} n p^{-1}(n=2,3,4)$ levels in $\mathrm{XBr}(\mathrm{X}=\mathrm{Na}, \mathrm{K}, \mathrm{Rb})$ molecules with pure atomic spin-orbit splittings. ${ }^{30}$ An atomic configuration $n p^{5}(n+1) s$ gives rise to 4 states due to coupling of $n p$ hole with $(n+1) s$ valence electron. In order to estimate atomic spin-orbit splitting we averaged energies of the states corresponding to $n p_{1 / 2}$ and $n p_{3 / 2}$ holes. As one can see from Fig. 2, calculated $\mathrm{Na} 2 p^{-1}$ and $\mathrm{K}$ $3 p^{-1}$ peaks do not have clear spin-orbit splittings and therefore the widths of the corresponding group of lines were taken as estimations. Instead, $\mathrm{Rb} 4 p^{-1}$ peak has clearly visible spinorbit splitting. The results are summarized in Table IV.

As seen from Table IV, the spin-orbit splitting of $\mathrm{Na} 2 p^{-1}$ and $\mathrm{K} 3 p^{-1}$ peaks is directly comparable with atomic spinorbit splitting, while $\mathrm{Rb} 4 p^{-1}$ spin-orbit splitting is most probably effected by contribution from $\mathrm{Br} 4 s^{-1}$ satellites. Overall correct reproduction of the inner-valence spectral features requires an adequate treatment of relativity and electron correlation.

\section{CONCLUSIONS}

We have studied the valence photoelectron spectra of alkali bromides $\mathrm{XBr}(\mathrm{X}=\mathrm{Li}, \mathrm{Na}, \mathrm{K}, \mathrm{Rb})$ within the framework of the propagator theory. The ADC(3) method is shown to be an effective tool in calculation of the inner-valence region for molecules where heavy elements are presented. The theoretically calculated valence ionization spectrum of potassium bromide is in good agreement with experiment.

$\mathrm{ADC}(3)$ theoretical calculations of the valence ionization spectra of $\mathrm{LiBr}, \mathrm{NaBr}$, and $\mathrm{RbBr}$ molecules were presented in this work for the first time and should have predictive character for future experimental investigation.

Discrepancy between the theoretical and experimental relative intensity might exist due to the fact that $\mathrm{ADC}(3)$ method does not take into account dipole matrix elements between bound one-particle state and the continuum state.

\section{ACKNOWLEDGMENTS}

This work has been supported by the Research Council for the Natural Sciences and Engineering of the Academy of Finland.

${ }^{1}$ J. Berkowitz, C. H. Batson, and G. L. Goodman, J. Chem. Phys. 71, 2624 (1979).

${ }^{2}$ A. W. Potts and E. P. F. Lee, J. Chem. Soc., Faraday Trans. 2 75, 941 (1979).

${ }^{3}$ J. Niskanen, S. Urpelainen, S. Aksela, H. Aksela, O. Vahtras, V. Carravetta, and H. Ågren, Phys. Rev. A 81, 043401 (2010).

${ }^{4}$ R. T. Poole, R. C. G. Leckey, J. G. Jenkin, and J. Liesegang, Chem. Phys. Lett. 31, 308 (1975). 
${ }^{5}$ A. W. Potts, T. A. Williams, and W. C. Price, Proc. R. Soc. London, Ser. A 341, 147-161 (1974).

${ }^{6}$ T. D. Goodman, J. D. Allen, Jr., L. C. Cusachs, and G. K. Schweitzer, J. Electron Spectrosc. Relat. Phenom. 3, 289-304 (1974).

${ }^{7}$ M. Patanen, J. Niskanen, M. Huttula, K. Jänkälä, S. Urpelainen, H. Aksela, and S. Aksela, J. Phys. B 41, 215103 (2008).

${ }^{8}$ E. Kukk, M. Huttula, H. Aksela, S. Aksela, E. Nömmiste, and A. Kikas, J. Phys. B: At. Mol. Opt. Phys. 36, L85 (2003).

${ }^{9}$ A. Caló, M. Huttula, M. Patanen, H. Aksela, and S. Aksela, J. Electron Spectrosc. Relat. Phenom. 162, 30 (2008).

${ }^{10}$ P. Tomasello and W. von Niessen, Europhys. Lett. 7, 405 (1988)

${ }^{11}$ M. Pernpointner and S. Knecht, Chem. Phys. Lett. 410, 423 (2005).

${ }^{12}$ M. Pernpointner, S. Knecht, and L. Cederbaum, J. Chem. Phys. 125, 034309 (2006).

${ }^{13}$ W. von Niessen, J. Schirmer, and L. S. Cederbaum, Comput. Phys. Rep. 1, 57-125 (1984).

${ }^{14}$ L. S. Cederbaum and W. Domke, Adv. Chem. Phys. 36, 205-344 (1977).

${ }^{15}$ J. Schirmer, L. S. Cederbaum, and O. Walter, Phys. Rev. A 28, 1237 (1983).

${ }^{16}$ D. Danovich, Wiley Interdiscip. Rev.: Comput. Mol. Sci. 1, 377-387 (2011).

${ }^{17}$ F. Tarantelli and L. S. Cederbaum, Phys. Rev. A 39, 1639 (1989).

${ }^{18}$ F. Tarantelli and L. S. Cederbaum, Phys. Rev. A 39, 1656 (1989).

${ }^{19}$ M. Pernpointner, J. Chem. Phys. 121, 8782 (2004).
${ }^{20}$ M. Pernpointner, J. Phys. B 43, 205102 (2010).

${ }^{21}$ T. Saue, L. Visscher, and H. J. Aa. Jensen, with contributions from R. Bast, K. G. Dyall, U. Ekström, E. Eliav, T. Enevoldsen, T. Fleig, A. S. P. Gomes, J. Henriksson, M. Iliaš, Ch. R. Jacob, S. Knecht, H. S. Nataraj, P. Norman, J. Olsen, M. Pernpointner, K. Ruud, B. Schimmelpfennig, J. Sikkema, A. Thorvaldsen, J. Thyssen, S. Villaume, and S. Yamamoto, DIRAC, a relativistic ab initio electronic structure program, Release DIRAC10, 2010, see http://dirac.chem.vu.nl.

${ }^{22}$ A. Honig, M. Mandel, M. L. Stitch, and C. H. Townes, Phys. Rev. 96, 629 (1954).

${ }^{23}$ F. J. Lovas and E. Tiemann, J. Phys. Chem. Ref. Data 3, 609 (1974).

${ }^{24}$ G. M. Rothberg, J. Chem. Phys. 34, 2069 (1961).

${ }^{25}$ R. Krishnan, J. S. Binkley, R. Seeger, and J. A. Pople, J. Chem. Phys. 72, 650 (1980).

${ }^{26}$ A. D. McLean and G. S. Chandler, J. Chem. Phys. 72, 5639 (1980).

${ }^{27}$ J.-P. Blaudeau, M. P. McGrath, L. A. Curtiss, and L. Radom, J. Chem. Phys. 107, 5016 (1997).

${ }^{28}$ K. G. Dyall, Theor. Chem. Acc. 115, 441 (2006); see http://dirac.chem. sdu.dk for basis sets available from the DIRAC web site.

${ }^{29}$ W. C. Price, A. W. Potts, and D. G. Streets, Electron Spectroscopy, edited by D. A. Shirley (North-Holland Publ. Co., Amsterdam, 1972), pp. 187198.

${ }^{30}$ NIST Atomic Spectra Database, version 5.0, see http://physics.nist. gov/asd. 